\title{
CHRONIC OBSTRUCTIVE PULMONARY DISEASE: PERSPECTIVES FOR PRIMARY HEALTH CARE
}

\author{
Ángel Emmanuel Vega-Sánchez, Norma A. Téllez-Navarrete and Rogelio Pérez-Padilla* \\ Department of Research in Tobacco and COPD, Instituto Nacional de Enfermedades Respiratorias Ismael Cosío Villegas, \\ Mexico City, Mexico
}

\begin{abstract}
Background: Chronic obstructive pulmonary disease (COPD) has become a major health challenge worldwide due to its increasing incidence and mortality, which have serious repercussions for health-care systems. Methods: We conducted a review of international efforts to control COPD in primary care. Results: The WHO created the Alma-Ata declaration which established for the first time, access to health care as a human right. This precept led to the implementation of numerous programs including practical approach to Lung Health and variants in several countries; schemes designed to centralize medical care; and resources to improve attention of respiratory diseases by adapting approaches to the health-care needs of local populations. Primary respiratory health care should include actions for timely detection, health education, and targeted treatment, but the challenge for all health systems is to ensure that their programs function adequately, for they still show shortcomings in terms of their application. Conclusions: We conclude that offering primary health care based on models that combine opportune diagnoses with suitable treatment can positively influence the course of COPD by treating early stages, thus slowing its progression. However, more extensive education and broader dissemination of information are necessary to achieve this goal. (REV INVEST CLIN. 2019;71:55-63)
\end{abstract}

Key words: Pulmonary disease. Chronic obstructive. Primary health care. Early diagnosis.

\section{INTRODUCTION}

\section{Definition and epidemiology of chronic obstructive pulmonary disease (COPD)}

COPD is defined as a common, preventable, and treatable condition characterized by airway obstruction that is not completely reversible with bronchodilators. It is caused mainly by inhaling smoke, especially from tobacco products. At present, together all forms of chronic pulmonary disease comprise the third-leading cause of death worldwide among non-communicable illnesses, led by COPD, which was responsible for 2.3 million deaths in 2016, according to the most recent Global Burden of Diseases report ${ }^{1-3}$. In medium-lowincome countries, it is the fourth-leading cause of death, while in high-income nations, it holds the fifth place $^{4}$. COPD represents a worldwide challenge to

Corresponding author:

*Rogelio Pérez-Padilla

Department of Research in Tobacco and COPD

Instituto Nacional de Enfermedades Respiratorias

Ismael Cosío Villegas (INER)

Calzada de Tlalpan, 4502

Col. Sección XVI, Del. Tlalpan

C.P. 14080, Mexico City, Mexico

E-mail: perezpad@gmail.com 
health systems, precisely because it is both preventable and treatable ${ }^{5}$. While medical specialists have elaborated several guides for managing COPD patients, few of them deal with primary health care ${ }^{6,7}$ where, logically, most such patients are detected and treated. Guidelines for clinical practice generally focus on defining: (1) the spectrum of at-risk populations and (2) suitable diagnostic criteria. Guidelines also stress the importance of managing modifiable factors; for example, by organizing workshops, talks and support groups for at-risk sectors where patients are encouraged to quit smoking or inhaling other harmful smokes $^{8}$.

\section{METHODS}

For this review, we conducted a systematic search of articles published between 1978 and 2018 using keywords from the Mesh dictionary in PUBMED/NIH, filtered for complete text documents. We then searched using the following term combinations: primary health care, pulmonary disease, and chronic obstructive disease. Of the 522 documents found, 75 were controlled studies and two were meta-analyses. For primary health care, pulmonary disease, chronic obstructive, and spirometry, 77 documents were located, six of which were controlled clinical studies.

\section{RESULTS}

\section{Poor adherence to guidelines for clinical practice in primary health care}

A multinational study conducted in Latin America by Laniado-Laborín et al. found poor application of existing guidelines at the primary level of health care $(\mathrm{PHC})$. The main causes cited were as follows: "l've never read them" ( $42 \%)$, "lack of access to information" (20\%), and "little time to read" (6\%). However, poor adherence to such recommendations is a global problem ${ }^{9}$. Discussing the use of the $\mathrm{FEV}_{1} / \mathrm{FVC}<0.70$ as criteria for airflow obstruction, Schermer and Quanjer observed that it generated a high number of false positives, so they suggested using the lower limit of normality (LLN) instead ${ }^{10}$. Takahashi et al. found that up to $31 \%$ of COPD patients that seek $\mathrm{PHC}$ does not receive any kind of treatment ${ }^{11}$. Other studies underscore factors such as poor adherence, inadequate understanding of guidelines, infrequent use of spirometry for diagnosis (mean $26 \%$; range $10-48 \%$ ), and distrust of X-rays as a diagnostic tool (mean 14\%; range $5-22 \%)^{12,13}$. An analysis of $\mathrm{PHC}$ in Germany found a significant disparity in the use of guidelines (Global Initiative for Chronic Obstructive Lung Disease [GOLD] vs. German PHC criteria for (OPD), and insufficient adherence to diagnostic measures, treatment programs, and patient education ${ }^{13}$. Studies in 56 primary care centers in Sweden documented inadequate implementation of established processes for detecting COPD patients coupled with poor follow-up on exacerbated cases ${ }^{14}$. The main obstacles to adherence to these guidelines include unfamiliarity and disagreement with recommendations due to perceptions of few benefits and inefficacy ${ }^{15}$.

\section{Social and economic burden of COPD}

COPD carries a huge social burden, considering the range of disability-adjusted life years (DALYs), an index that totals the years lost to premature death plus the years of life with disability. COPD was once the eighth-leading cause of DALYs worldwide, but by 2013 it rose to the third place. Europe invests $€ 38.6$ billion to treat this disease, a figure that represents $56 \%$ of all outlays on respiratory ailments. The U.S. has a similar level of spending ( $\$ 50$ billion USD), of which a significant percentage goes to treat exacerbated cases $^{5}$. Finally, health-care systems rarely provide chronic care to patients in advanced stages of COPD, an omission that affects not only the patients themselves but also people around them at work and at home who must help care for their ill family member. Clearly, this has consequences for both the family's economy and the community as a whole.

\section{Diagnosing COPD}

COPD diagnosis of at-risk patients is confirmed by post-bronchodilator spirometry that detects an obstructive pattern $\left(\mathrm{FEV}_{1} / \mathrm{FVC}\right.$ relation $<0.7$, or $<\mathrm{LLN}$ the lower fifth percentile of age- and gender-adjusted $\left.\mathrm{FEV}_{1} / \mathrm{FVC}\right)^{16}$. The most common risk factors are smoking, exposure to solid-fuel smoke, workplace exposure, and genetic factors. Disease severity is expressed as the degree of obstruction estimated by $\mathrm{FEV}_{1}$ expressed as percentage of predicted ${ }^{5,6,8,17}$, although emphasis has recently shifted to giving greater importance to respiratory symptoms or 
multidimensional indices like BODE, which considers the body mass index (BMI), the degree of obstruction assessed by $\mathrm{FEV}_{1}$, the 6 min walking distance, and the severity of dyspnea. The practice of using spirometry should not be limited to respiratory specialists. Indeed, it is necessary that the first-contact physicians have access to this test, given the high prevalence of COPD in middle-aged populations who present with dyspnea, coughing, or chest tightness or wheezing, which may appear in as many as three of every 10 individuals going to primary care, being more frequent in men ${ }^{18}$. Smokers can also be monitored using spirometry. Although in a study in Spain in primary health care, up to $16 \%$ of asymptomatic patients were diagnosed with COPD during 3 years of followup, they had a heavy smoking history: 31 pack-years on average. In addition, $22 \%$ of smokers studied stopped smoking during the 3 years of follow-up ${ }^{19}$. The American Association of Family Physicians recommends spirometry to diagnose COPD in patients with symptoms or signs or with risk factors for COPD $^{20}$. One study of 278 family physicians found that $76 \%$ reported using spirometry to diagnose COPD, but only $32 \%$ utilized post-bronchodilator spirometry ${ }^{21}$. Using spirometry without the bronchodilator can increase COPD diagnosis by as much as 30\%, likely including patients with bronchial asthma and reversible obstruction ${ }^{22}$. Observations in 12 primary health care centers in the U.S. showed that $71 \%$ of spirometry procedures were interpreted appropriately, and $76 \%$ of those interpretations agreed with respirologists. However, only $48 \%$ of the results led to modifying the treatment prescribed ${ }^{23}$. In developing countries, the use of spirometry in at-risk patients was seen in $26 \%$ of cases $^{12}$, but this figure was as low as $10 \%$ in PHC in studies in Asia, which revealed that even specialists may use spirometry in only $50 \%$ of cases $^{24}$. In Mexico, general practitioners seldom use spirometry ${ }^{12}$, and some studies suggest that merely $34 \%$ follow the GOLD guidelines ${ }^{9}$.

\section{Case finding and screening for COPD}

Screening asymptomatic patients who have risk factors for a disease, whether genetic, environmental, including occupational ${ }^{5}$ can have a huge impact on health. Workers exposed to smoke have a higher risk of developing COPD $(1.64 ; 95 \% \mathrm{Cl}, 1.25-2.14)$ than non-exposed individuals ${ }^{25}$, so it is reasonable to argue that a search strategy applied to identify cases, instead of simply diagnosing symptomatic patients, would bring greater benefits to the general population. A strategy designed to detect asymptomatic COPD cases found that in at-risk individuals over 35 years old, this was more effective ${ }^{26}$, especially if a spirometry is combined with a questionnaire ${ }^{27}$. Jordan et al., combining a survey and peak flow meters, found that the number of new cases diagnosed in their study group was greater than in a control group (5\% vs. $2 \%$, OR 2.34 [2.06-2.66]; $p<0.0001$ ) and that cost-effectiveness improved ( $€ 333$ vs. $€ 376)^{28}$. A study conducted in Japan that applied a screening strategy to detect cases with follow-up on patients aged 40 and over in the form of regular visits and use of a portable spirometer generated a sensitivity of $40.7 \%$, a specificity of $96.4 \%$, a PPV of $78.6 \%$, and an NPV of $83.5 \%{ }^{29}$. These results clearly indicate the need to screen subjects with risk factors in the fourth decade of life and not simply diagnose already symptomatic cases.

\section{Benefits of primary care}

In September 1978, the WHO issued a call to health systems worldwide to guarantee health care as a universal right and to explore related social, economic, and political factors in their respective countries. The proposal urged national states to promote and protect health not only as a right of individuals but also as an indispensable factor for economic and social development. The Alma-Ata Declaration proposed reaching these objectives by orienting $\mathrm{PHC}$ to ameliorate the most pressing problems of each community and emphasize self-responsibility and local participation $^{30}$. In 1988, the WHO reviewed the advances of Alma-Ata, considering in addition issues of universal health coverage, vaccination campaigns, and maternal and infant mortality. The report revealed a huge gap between developed and developing countries ${ }^{31}$. In 2008, the United Nations' consensus after 30 years of the Alma-Ata Declaration was republished to reinforce its principles, taking into account social changes in the world since $1978^{32}$ and insisting on the indispensable need for broad, high-quality PHC programs for communities worldwide ${ }^{33}$. The key characteristics underscored in that report are promoting health, universal coverage centered on people, solidarity, social inclusion, and greater decision-making at the community level. 


\section{Primary care schemes for COPD}

Several proposals for primary care exist, but they differ in how they seek to incorporate the care of respiratory illnesses, including COPD. Programs for COPD primary care include single-subject programs (only COPD), integrated respiratory schemes (several respiratory diseases), and programs dealing with a variety of health problems among which COPD is included.

\section{Specific primary care programs for COPD}

Finland established a National Program for Chronic Bronchitis and COPD whose main objectives were to improve diagnosis in PHC to reduce: disease prevalence, the number of moderate-to-severe cases, the frequency of hospitalizations, and treatment costs ${ }^{34}$. This program includes guidelines on smoking and spirometry use and efforts to enact anti-smoking legislation. Reported results include a $39.7 \%$ reduction in days spent in hospital and lower costs of medical care. The prevalence of smoking among men decreased from $30 \%$ to $26 \%$, although this change did not modify the prevalence of COPD or its level of mortality. This scheme did, however, quickly contribute to improving detection and reducing the number of moderate-to-severe cases $^{34}$. The WHO judged this program a success but suggested that integrating other illnesses would ensure its long-term viability while reducing redundancies and overlaps ${ }^{33}$. Because implementing specific programs for individual illness are clearly unviable, it is necessary to formulate integrated programs. Another problem with single-subject plans for COPD like the one in Finland is that they compete for attention and resources with programs that manage other diseases, perhaps even some in the same area of specialization. Obviously, this could threaten their long-term sustainability.

\section{Integrated respiratory care programs}

Practical Approach to Lung Health (PAL) was created as a proposal for a comprehensive syndromic approach to respiratory symptoms that would expand services through existing tuberculosis clinics around the world ${ }^{35}$. One premise was that people with cough or phlegm who tested negative for tuberculosis would be invited to take a broader evaluation to determine the cause of their symptoms. This scheme has been implemented in several nations where it has reduced treatment costs, improved control of tuberculosis, and lessened both the use of antibiotics to treat acute respiratory infections and the frequency of referrals to higher levels of medical care ${ }^{35}$. Of course, PAL must be adapted to the specific conditions that exist in each country based on assessments of their baseline situation and, later, of their post-intervention results. South Africa's version of the program - called PAL Health in South Africa (PALSA) - for example, includes guidelines for diagnosing and treating four respiratory diseases (tuberculosis, COPD, and upper and lower airway infections). It takes a syndromic approach, applies diagnostic algorithms ${ }^{36}$, and includes a training program for nurses designed and supervised by physicians, anthropologists, and researchers, which set out to develop a personalized form of instruction accompanied by continuous evaluation of results in the population ${ }^{37}$. This program was later broadened to include HIV/AIDS patients and called PALSA PLUS. It achieved a much greater impact than routine approaches adopted in typical health centers (OR 1.25, $95 \% \mathrm{Cl}: 1.01-1.55)^{38}$. PALSA PLUS results have demonstrated efficacy in primary care in terms of diagnoses and the breadth of coverage of antiretroviral therapy. Today, nurses also benefit from this training program ${ }^{39}$. Respiratory programs of this kind have many advantages for family doctors who do not focus on one single disease but are trained to attend patients' main respiratory problems. Implementing such respiratory programs, however, entails competing with other disease groups that may receive more substantial resources from states. For these reasons, the creation of integrated primary health-care centers has better long-term perspectives.

\section{Integrated primary health-care programs that include respiratory diseases}

The $\mathrm{WHO}$ has produced programs for non-communicable diseases (NCD) like the recently instituted package essential NCD, which focuses on chronic respiratory, cardiovascular, and metabolic diseases ${ }^{40}$. While, in principle, it would seem to have advantages over other approaches developed earlier to deal with acute and chronic illnesses, we do not yet have any studies or evaluations of its implementation and effectiveness. The Knowledge Translation Unit of the pulmonary institute at the University of Cape Town 
developed the adult practical approach to care kit (PACK) program that has proven effective in enhancing PHC in South Africa. Designed as an extension of the PALSA PLUS system to include NCD (or NCD, such as hypertension, diabetes, and cardiovascular disease), mental health, palliative care, and women's health, it incorporates guidelines based on evidence, applicable policies, team training through analysis of clinical cases at its work centers, prescriptions by non-medical health personnel, and a cascade system applied to the jurisdiction. The starting point of the specific tool involved requires evaluating symptoms with algorithms, combined with completing information forms that include a verification list which helps health workers assess and advise patients, and then treat their chronic conditions. The training program emphasizes continuous education, short visits to clinics by trained personnel, facilitating information flows, and inviting teams of professional health workers to participate in the daily application of the PACK program ${ }^{41}$. PACK has also been adapted and implemented in Botswana, while Malawi, Gambia, Brazil, and Mexico have tested pilot PALSA PLUS programs. Given the evidence of the efficacy of such approaches, their use could be extended to many countries, although this would entail adapting guidelines to each community's needs and integrating them with local policies ${ }^{41}$. Integrated programs of this kind fulfill the WHOs proposals and greatly reduce competition among interest groups associated with different diseases because their success depends largely on achieving a consensus that is respected and promoted by everyone involved. Adequate PHC is urgently required throughout the world, regardless of individual countries' levels of development. South Africa's efforts to adapt the plan are remarkable, while Finland's program required restructuring and decentralizing the health-care system to favor primary care centers supported by sufficient state funding and legislation to guarantee that health policies will center on local needs ${ }^{42}$. Australia provides another example of the integration of a primary care health system made necessary, in part, by its very diverse geographic and social regions characterized by enormous variations in disease prevalence and incidence. This heterogeneity coupled with a health system subsidized by both the public and private sectors, demands integrating all health systems with the support of health education resources and preventive medicine ${ }^{43}$.

\section{Essential medicines and medical equipment recommended by the WHO for chronic pulmonary diseases}

The WHOs chart of essential medicines is a document that orients countries in the purchase of a group of basic medicines, including a limited number of respiratory drugs for treating COPD and asthma, namely beclomethasone, budesonide/formoterol, epinephrine, salbutamol, and ipratropium bromide ${ }^{44}$. Unfortunately, this list omits long-acting bronchodilators and antimuscarinics that many studies -mostly conducted in developed or medium-income countries - have shown are effective in preventing exacerbations and improving patients' quality of life ${ }^{5}$. In this regard, it is important to perform cost-benefit studies that consider the economic conditions of developing countries, as these could produce quite different results from those generated in developed nations. Another aspect drawing our attention is that the WHO specifies as "basic medical equipment" for testing the respiratory function devices which analyze gas diffusion and measure airway resistance or total pulmonary volume, like the plethysmograph ${ }^{45}$. These devices are not used routinely but are only available in specialized health centers. Thus, greater emphasis must be placed on the spirometer and the pulse oximeter as the main diagnostic tools because of portability and cost, and health personnel must become familiar with their features and limitations.

\section{Primary health care in countries with socialized medicine}

Programs of medical care that offers universal access to health are based on integrated schemes that cover a full range of diseases, among them, COPD. Because of COPDs high incidence in Sweden, specialized centers exist to offer primary care that includes spirometry and trained nursing personnel. This approach has reduced the number of exacerbations from 2.2 to 0.9 visits $/$ year $^{46}$, despite the limited use of spirometry (available at only $50 \%$ of centers), and a moderate anti-smoking advice (50\%), increased influenza vaccinations $(60 \%)$, and substantially lowered the number of referrals to pulmonary rehabilitation $(19 \%)^{47}$.

In Switzerland, discrepancies between PHC guidelines and real practice were found, especially with respect 
to educating COPD patients, referrals to pulmonary rehabilitation, and erroneous prescription of inhaled corticosteroids in $38 \%$ of mild cases and $43 \%$ of moderate ones ${ }^{48}$.

In Denmark's health-care service, $99 \%$ of citizens are registered at state-funded primary care centers ${ }^{49}$; despite the high prevalence of COPD, $74 \%$ of patients never consulted a doctor on feeling the initial symptoms of this disease $\mathrm{e}^{50}$. This has led to greater emphasis being placed on detecting asymptomatic patients with risk factors ${ }^{51,52}$, including a screening project implemented in Copenhagen based on exposure to smoking and the presence of dyspnea, chronic coughing, and sputum ${ }^{53}$. When a person with COPD is detected, the patient is referred to a pulmonary rehabilitation program at a primary care center. This project, called KOALA, has shown excellent acceptance and functionality ${ }^{54}$.

France's health system was funded with payments from workers and employers and is operated by statecontrolled insurance companies that pay doctors' fees, which causes that physicians concentrate in the cities rather than the communities ${ }^{55}$. The use of spirometry in PHC was judged to be inefficient due to the time required to perform testing ( $15.2 \pm 5.9 \mathrm{~min}$ ) and the often low quality of tests ( $58 \%$ of all spirometries have curves and only $30 \%$ are deemed acceptable $)^{56}$. The lack of timely diagnosis of COPD prevents patients from consulting physicians and beginning treatment opportunely, thus increasing the economic costs of the disease ${ }^{57,58}$.

In summary, even countries with socialized medicine and universal access to health services have limitations in terms of adequate care of COPD patients, including poor spirometry use and insufficient efforts to ensure timely detection and begin preventive care.

\section{Initiatives in Mexico}

Mexico's health-care system has a standardized program for detecting tuberculosis in persons with respiratory symptoms (cough or phlegm), but most subjects who receive negative test results (smear acid-fast bacilli search) are discharged without followup $^{59}$. In 2017, the National Institute of Respiratory Diseases elaborated the AIRE guidelines (integral action for respiration) based on PALSA but adapted to local conditions. AIRE was developed for use by primary care physicians, analyzing respiratory symptoms, daytime somnolence, and smoking, diagnosis of asthma or COPD, or suspicions of tuberculosis/HIV. Many primary care physicians in Mexico city and several states have received training in the AIRE program. Recently, Mexico's Federal Department of Health implemented the Specific Action Program for the Prevention and Control of Respiratory Diseases and Influenza (PAE-ERI). Its objectives are to prevent acute cases of pneumonia and influenza while providing primary care for up to $80 \%$ of asthma and COPD patients ${ }^{60}$.

\section{Guidelines for treating COPD in primary care}

In 1997, a panel of experts began to meet to create the GOLD standard and develop the now well-known international COPD guidelines (2001), which establish norms for diagnosing, managing, treating, and preventing this disease. In addition, it establishes goals for reducing the number of exacerbations and hospitalizations ${ }^{61}$. This approach received criticisms because it provides few recommendations for primary care, palliative care, and treatment of such comorbidities as depression, anxiety, and social impact ${ }^{62}$. The pocket-sized version of GOLD is more useful for $\mathrm{PHC}$ personnel, as it emphasizes non-pharmacological treatments including adherence to supplementary oxygen, vaccination, education, self-care, exercise, nutrition, and orientations on palliative care. The COPD-X Plan by the Thoracic Association of Australia and New Zealand and Australia's Lung Foundation ${ }^{63}$ were disseminated to all health-care personnel involved in caring for COPD patients. They summarize the key points of primary care, namely diagnoses by spirometry, suspected COPD in people $>35$ years old with a history of smoking or workplace exposure to gases and dust, support to help patients quit smoking, referrals to pulmonary rehabilitation services, advice to take the influenza vaccination annually, and pneumococcal immunization. Moreover, they recommend developing an action plan that helps patients recognize the signs of exacerbation and immediately seek attention, invites them to verify their medications, and refers them to local Lung Foundations for group support and education ${ }^{64}$. 
Britain's National Institute for Health and Care Excellence created COPD guidelines for first- and secondlevel health care in 2004. Designed for PHC, it recommends - in all cases - quitting smoking, offering education, evaluating comorbidities, measuring the $\mathrm{BMI}$, promoting exercise and vaccinations, recognizing the symptoms of exacerbation, evaluating functional limitations and hypoxemia, providing social support, and assessing options for palliative care ${ }^{65}$. The Guidelines for Diagnosing and Managing COPD for PHC were issued by the International Primary Care Respiratory Group. While they largely follow the GOLD approach, they also focus on the resources to which first-level doctors have access ${ }^{66}$. Today, this organization is devoted to disseminating research, training health personnel to develop abilities in education, evaluating the most useful diagnostic tools, doing follow-up on COPD patients, and assessing $\mathrm{PHC}$ initiatives like the "pilot" multidisciplinary educational program for diagnosing and managing asthma and COPD that was tested in Sao Paulo, Brazil, as part of wider efforts to treat this disease and improve patient handling by organizing workshops and groups discussions with professionals from various fields ${ }^{67}$.

The PROMET study (Madrid's Telehealth Project for COPD) demonstrated the effectiveness of in-house monitoring by a telemedicine program in patients with severe $\mathrm{COPD}^{68}$, by significantly reducing the number of hospitalizations. The EDGE-platform (Self-management and Support Program) ${ }^{69}$ and COMET (European trial for COPD patient management) aim to assess in-home self-care programs supported by electronic media and online platforms ${ }^{70}$. The use of online rehabilitation in the CORE trial study demonstrated benefits compared to other common approaches ${ }^{71}$. While resources of this kind could be used to support PHC, this would require larger investments in health-care systems in this field accompanied by guarantees of sustainability.

\section{CONCLUSIONS}

The importance of implementing programs such as the ones mentioned in this review in primary health care lies in the expansion of the population over 65 years of age, which has reached an annual rate of $3.8 \%$. This means that by 2025 this sector will outnumber the childhood population and bring an increase in the incidence of chronic respiratory diseas$\mathrm{es}^{72}$. Caring for COPD and other common non-communicable but high incidence illnesses (diabetes, cardiovascular, and cerebrovascular disease) demands the participation of primary care because it far exceeds the capacity of specialists in the field. Providing comprehensive care to handle the most common respiratory illnesses, including COPD, appears to be the best option for most regions of developing countries, compared to single-subject programs. Indeed, it seems clear that an integral primary care program that covers the main respiratory and non-respiratory health problems has many advantages over other approaches.

\section{REFERENCES}

1. Murray CJL, Lopez AD. Measuring global health: motivation and evolution of the global burden of disease study. Lancet. 2017;390:1460-4

2. GBD 2016 DALYs and HALE Collaborators. Global, regional, and national disability-adjusted life-years (DALYs) for 333 diseases and injuries and healthy life expectancy (HALE) for 195 countries and territories, 1990-2016: a systematic analysis for the global burden of disease study 2016. Lancet. 2017;390:1260-344

3. GBD 2016 Mortality Collaborators. Global, regional, and national under-5 mortality, adult mortality, age-specific mortality, and life expectancy, 1970-2016: a systematic analysis for the global burden of disease study 2016. Lancet. 2017; 390:1084-150.

4. WHO. The Top Causes of Death. WHO. 2017. Available from: http://www.who.int/news-room/fact-sheets/detail/the-top10-causes-of-death.

5. Global Initiative for Chronic Obstructive Lung Disease Global Strategy for the Diagnosis, Management, and Prevention of Chronic Obstructive Pulmonary Disease (2018 Report). Available from: https://www.goldcopd.org/wp-content/uploads/2017/ 11/GOLD-2018-v6.0-FINAL-revised-20-Nov_WMS.pdf. [Last accessed on june 6,2018 ].

6. Grupo de trabajo para las guías de EPOC. Guías Para el Diagnóstico y Tratamiento de la Enfermedad Pulmonar Obstructiva Crónica. Neumol Cir Torax. 2012;71: 1-84.

7. Alvarado A, Gamiño-Pérez A, Nájera-Cruz M, Rodríguez-Praga D, Sánchez-Mecatl M, Torres-Arreola L. Guía de Práctica Clínica Diagnóstico y Tratamiento de la Enfermedad Pulmonar Obstructiva Crónica. 2009. Available from: http://www.cenetec.salud. gob.mx/interior/gpc.html. [Last accessed on june 6, 2018].

8. Guía de Práctica Clínica Diagnóstico y Tratamiento de la Enfermedad Pulmonar Obstructiva Crónica. Available from: http:// www.imss.gob.mx/sites/all/statics/guiasclinicas/037GER.pdf. [Last Accessed on june 6, 2018].

9. Laniado-Laborín R, Rendón A, Alcantar-Schramm JM, CazaresAdame R, Bauerle O. Subutilization of COPD guidelines in primary care. J Prim Care Community Health 2013;4:172-6.

10. Schermer TR, Quanjer PH. COPD screening in primary care: who is sick? Prim Care Respir J. 2007;16:49-53.

11. Takahashi T, Ichinose M, Inoue $\mathrm{H}$, et al. Underdiagnosis and undertreatment of COPD in primary care settings. Respirology. 2003;8:504-8

12. Aisanov Z, Bai C, Bauerle O, et al. Primary care physician perceptions on the diagnosis and management of chronic obstructive pulmonary disease in Diverse regions of the world. Int J Chron Obstruct Pulmon Dis. 2012;7:271-82.

13. Glaab T, Banik N, Rutschmann OT, Wencker M. National survey of guideline-compliant COPD management among pneumologists and primary care physicians. COPD. 2006;3:141-8. 
14. Sundh J, Österlund Efraimsson E, et al. Management of COPD exacerbations in primary care: a clinical cohort study. Prim Care Respir J. 2013;22:393-9.

15. Perez X, Wisnivesky JP, Lurslurchachai L, Kleinman LC, Kronish IM. Barriers to adherence to COPD guidelines among primary care providers. Respir Med. 2012;106:374-81.

16. Miller MR, Hankinson J, Brusasco V, et al. Standardisation of spirometry. Eur Respir J. 2005;26:319-38.

17. Peces-Barba G, Albert Barberà J, Agustí À, et al. Guía clínica SEPAR-ALAT de diagnóstico y tratamiento de la EPOC. Arch Bronconeumol. 2008:44:229-86.

18. Abramson M, Matheson M, Wharton C, Sim M, Walters EH. Prevalence of respiratory symptoms related to chronic obstructive pulmonary disease and asthma among middle aged and older adults. Respirology. 2002;7:325-31

19. Clotet J, Gómez-Arbonés X, Ciria C, Albalad JM. Spirometry is a good method for detecting and monitoring chronic obstructive pulmonary disease in high-risk smokers in primary health care. Arch Bronconeumol. 2004;40:155-9.

20. Stoloff SW. Diagnosis and treatment of patients with chronic obstructive pulmonary disease in the primary care setting: focus on the role of spirometry and bronchodilator reversibility. J Fam Pract. 2011;60:S9-16

21. Yawn BP, Wollan PC. Knowledge and attitudes of family physicians coming to COPD continuing medical education. Int J Chron Obstruct Pulmon Dis. 2008;3:311-7.

22. Menezes AM, Perez-Padilla R, Jardim JR, et al. Chronic obstructive pulmonary disease in five latin american cities (the PLATINO study): a prevalence study. Lancet. 2005;366:1875-81.

23. Yawn BP, Enright PL, Lemanske RF Jr., et al. Spirometry can be done in family physicians' offices and alters clinical decisions in management of asthma and COPD. Chest 2007;132: 1162-8

24. Vanjare N, Chhowala S, Madas S, et al. Use of spirometry among chest physicians and primary care physicians in India. NPJ Prim Care Respir Med. 2016;26:16036

25. Doney B, Hnizdo E, Syamlal G, et al. Prevalence of chronic obstructive pulmonary disease among US working adults aged 40 to 70 years. National health interview survey data 2004 to 2011. J Occup Environ Med. 2014;56:1088-93

26. Haroon SM, Jordan RE, O'Beirne-Elliman J, Adab P. Effectiveness of case finding strategies for COPD in primary care: a systematic review and meta-analysis. NPJ Prim Care Respir Med. 2015 ; 25:15056.

27. Haroon S, Jordan R, Takwoingi Y, Adab P. Diagnostic accuracy of screening tests for COPD: a systematic review and metaanalysis. BMJ Open. 2015;5:e008133

28. Jordan RE, Adab P, Sitch A, et al. Targeted case finding for chronic obstructive pulmonary disease versus routine practice in primary care (TargetCOPD): a cluster-randomised controlled trial. Lancet Respir Med. 2016;4:720-30.

29. Kobayashi S, Hanagama M, Yanai M, Ishinomaki COPD Network (ICON) Investigators. Early detection of chronic obstructive pulmonary disease in primary care. Intern Med. 2017;56: 3153-8.

30. Declaration of Alma-Ata. WHO 1978. Available from: http:// www.who.int/publications/almaata_declaration_en.pdf. [Last accessed on june 6, 2018]

31. WHO. From Alma-Ata to the Year 2000. WHO; 1988. Available from: http://www.apps.who.int/iris/bitstream/10665/39323/ 1/9241561246_eng.pdf. [Last accessed on june 6, 2018].

32. Chan M. OMS Regreso a Alma-Ata. WHO; 2013. Available from: http://www.who.int/dg/20080915/es/. [Last accessed on june 6, 2018].

33. OMS. Now More Than Ever. WHO; 2008. Available from: http:// www.who.int/whr/2008/whr08_en.pdf. [Last accessed on june 6, 2018].

34. Kinnula VL, Vasankari T, Kontula E, et al. The 10-year COPD programme in Finland: effects on quality of diagnosis, smoking, prevalence, hospital admissions and mortality. Prim Care Respir ]. 2011;20:178-83

35. WHO. Practical Approach to Lung Health (PAL). WHO; 2013. Available from: http://www.who.int/tb/health_systems/pal/ en/. [Last accessed on june 6, 2018].

36. English RG, Bateman ED, Zwarenstein MF, et al. Development of a South African integrated syndromic respiratory disease guideline for primary care. Prim Care Respir J. 2008;17:156-63.

37. Bheekie A, Buskens I, Allen S, et al. The practical approach to lung health in South Africa (PALSA) intervention: respiratory guideline implementation for nurse trainers. Int Nurs Rev. 2006:53:261-8.
38. Zwarenstein M, Fairall LR, Lombard C et al. Outreach education for integration of HIV/AIDS care, antiretroviral treatment, and tuberculosis care in primary care clinics in South Africa: PALSA PLUS pragmatic cluster randomised trial. BMJ. 2011;342:d2022.

39. Stein J, Lewin S, Fairall L, et al. Building capacity for antiretroviral delivery in South Africa: A qualitative evaluation of the PALSA PLUS nurse training programme. BMC Health Serv Res. 2008;8:240.

40. WHO. Prevention and Control of Noncommunicable Diseases: guidelines for Primary Health Care in Low-resource Settings. Available from: http://www.apps.who.int/iris/bitstream/ 10665/76173/1/9789241548397_eng.pdf. [Last accessed on june 6,2018$]$

41. Fairall L, Bateman E, Cornick R, et al. Innovating to improve primary care in less developed countries: towards a global model. BMJ Innov. 2015:1:196-203.

42. Kokko S. Integrated primary health care: Finnish solutions and experiences Background: how Finland chose the health centre model for primary care. Int J Integr Care. 2009;9:1568-4156.

43. Glasgow N. Systems for the management of respiratory disease in primary care - An international series: Australia. Prim Care Respir J. 2008;17:19-25

44. WHO. The Selection and Use of Essential Medicines Report of the WHO Expert Committee, 2017 (including the 20 ${ }^{\text {th }}$ WHO Model List of Essential Medicines and the 6th Model List of Essential Medicines for Children). WHO Tech Rep Ser 2017. [Last accessed on june 6, 2018].

45. WHO. Core Medical Equipment. Available from: http://www who.int/medical devices/en/index.html.

46. Löfdahl CG, Tilling B, Ekström $T$, et al. COPD health care in Sweden - A study in primary and secondary care. Respir Med. 2010;104:404-11.

47. Thorn J, Norrhall M, Larsson R, et al. Management of chronic obstructive pulmonary disease (COPD) in primary care: a questionnaire survey in Western Sweden. Prim Care Respir J. 2008, $17: 26-31$

48. Steurer-Stey C, Dallalana K, Jungi M, Rosemann T. Management of chronic obstructive pulmonary disease in Swiss primary care room for improvement. Qual Prim Care. 2012;20:365-73.

49. Christiansen T. Organization and financing of the Danish health care system. Health Policy. 2002;59:107-18

50. van den Boom G, Rutten-van Mölken MP, Tirimanna PR, et al Association between health-related quality of life and consultation for respiratory symptoms: results from the DIMCA programme. Eur Respir J. 1998;11:67-72.

51. Nielsen L, Elbrønd J. COPD treatment in general practice in Denmark is into a rapid development. Ugeskr Laege. 2013;175: 1271-6.

52. Bredesen H, Lous J. Smoking cessation with special focus on primary health care. Ugeskr Laeger. 2009;171:683-8.

53. Lyngsø AM, Gottlieb V, Backer V, et al. Early detection of COPD in primary care: the Copenhagen COPD screening project. COPD 2013;10:208-15.

54. Godtfredsen NS, Grann O Larsen HB, et al. Chronic obstructive pulmonary disease (COPD) rehabilitation at primary health-care centres - the KOALA project. Clin Respir J. 2012;6:186-92.

55. Sánchez-Sagrado T. La atención primaria en Francia. Semer Med Fam. 2016:42:58-62.

56. Giraud V, Beauchet A, Gomis T, Chinet T. Feasibility of spirometry in primary care to screen for COPD: a pilot study. Int ] Chron Obstruct Pulmon Dis. 2016;11:335-40.

57. Piperno D, Huchon G, Pribil C, Boucot I, Similowski T. The burden of COPD in France: results from the confronting COPD survey. Respir Med. 2003:97 Suppl C:S33-42.

58. Meeraus W, Jakubanis R, Wood R, Holbrook T, Punekar $Y$, Ismaila $A$, et al. The cost burden of COPD in France: a retrospective analysis of an administrative primary care database. In ethic and economics. Eur Respiratory Soc. 2017;50:PA2787.

59. Pérez-Padilla R. Hacia un programa de prevención y atención primaria de enfermedades respiratorias, AIRE a (acción integrada por la respiración). Neumol Cir Torax. 2012;71:244-9.

60. Sectorial De Salud P. Prevención y Control de las Enfermedades Respiratorias e Influenza. 2013. Available from: http://www. cenaprece.salud.gob.mx/descargas/pdf/PAE PrevencionControlEnfermedadesRespiratoriasInfluenza2013 2018.pd. [Last accessed on june 6, 2018].

61. GOLD. About Us - Global Initiative for Chronic Obstructive Lung Disease - GOLD. Available from: http://www.goldcopd.org/ about-us/. [Last accessed on june 6, 2018].

62. Price $D$, West $D$, Brusselle $G$, et al. Management of COPD in the UK primary-care setting. an analysis of real-life prescribing patterns. Int J Chron Obstruct Pulmon Dis. 2014:9:889-904. 
63. Yang IA, Dabscheck E, George J, et al. The origins of the COPD$X$ guidelines | COPD-X Lung Foundation Australia. 2005. Available from: https://www.copdx.org.au/copd-x-plan/the-originsof-the-copd-x-guidelines/. [Last accessed on june 6, 2018].

64. Lung Foundation Australia. COPD-X Concise Guide for Primary Care Lung Foundation Australia. Available from: https://www.lungfoundation.com.au/health-professionals/guidelines/copd/copd-xconcise-guide-for-primary-care/. [Last accessed on june 6, 2018].

65. Uptake Chronic Obstructive Pulmonary Disease: management of Chronic Obstructive Pulmonary Disease in Adults in Primary and Secondary Care Guidance and Guidelines NICE. Available from: https://www.nice.org.uk/guidance/CG101/uptake. [Last accessed on june 6,2018$]$.

66. Halbert RJ, Isonaka S. International primary care respiratory group (IPCRG) guidelines: integrating diagnostic guidelines for managing chronic respiratory diseases in primary care. Prim Care Respir J. 2006:15:13-9.

67. McDonnell J, de Sousa JC, De Sousa JC, et al. Building capacity to improve respiratory care: the education strategy of the international primary care respiratory group 2014-2020. NPJ Prim Care Respir Med. 2014;24:14072.
68. Segrelles Calvo G, Gómez-Suárez C, Soriano JB, et al. A home telehealth program for patients with severe COPD: the PROMETE study. Respir Med. 2014;108:453-62.

69. Farmer A, Toms C, Hardinge M, Williams V, Rutter H, Tarassenko L. Self-management support using an Internet-linked tablet computer (the EDGE platform)-based intervention in chronic obstructive pulmonary disease: protocol for the EDGE-COPD randomised controlled trial. BMJ Open. 2014; 4:e004437.

70. Bourbeau J, Casan P, Tognella S, et al. An international randomized study of a home-based self-management program for severe COPD: the COMET. Int J Chron Obstruct Pulmon Dis. 2016;11:1447-51.

71. Hansen $\mathrm{H}$, Bieler $\mathrm{T}$, Beyer $\mathrm{N}$, et al. COPD online-rehabilitation versus conventional COPD rehabilitation - rationale and design for a multicenter randomized controlled trial study protocol (CORe trial). BMC Pulm Med. 2017;17:140.

72. Ferreira-Guerrero EE. Enfermedad Respiratoria en Adultos. Reto Para la Salud Pública de México. 2018. Available from: https:// www.insp. $\mathrm{x}$ /avisos/3827-enfermedad-respiratoria-adultos. html. [Last accessed on june 6, 2018]. 